\title{
Optimisation of waste vegetable oill-based thermoset polymers
}

Felipe C. Fernandes MSC

PhD student, Sustainable Materials and Manufacturing Group, Warwick Manufacturing Group, University of Warwick, Coventry, UK

Kerry Kirwan EngD

Professor, Sustainable Materials and Manufacturing Group, Warwick Manufacturing Group, University of Warwick, Coventry, UK
Peter R. Wilson PhD

Postdoctoral Research Fellow, Sustainable Materials and Manufacturing Group, Warwick Manufacturing Group, University of Warwick, Coventry, UK

Stuart R. Coles PhD

Associate Professor, Sustainable Materials and Manufacturing Group, Warwick Manufacturing Group, University of Warwick, Coventry, UK (corresponding author: stuart.coles@warwick.ac.uk)

Bio-based thermoset polymers were produced from epoxidised waste vegetable oils (WVOs) cured with anhydrides at different molar ratios. Properties were compared to analogues produced with neat oil and diglycidyl ether of bisphenol $A$ as a feedstock. The thermal stability proved to be affected by the molar ratio, and the use of feedstock from waste oil resulted in no effect on this property. A dynamic mechanical analysis has shown that higher concentrations of anhydride enhance the storage modulus, glass transition temperature (up to $42.5^{\circ} \mathrm{C}$ ) and cross-link density. The frying process proved to play a minor role in tuning the dynamic mechanical properties. However, the contribution of the anhydride was demonstrated to be significant enough to mitigate the losses caused by the waste oil, as shown statistically in a design of experiment study. All formulations were chemically resistant to aqueous, organic and acidic media. The identification of the effects of critical parameters on the properties of WVObased thermosets enables the further production of polymers from waste streams.

\section{Notation}

$E^{\prime} \quad$ storage modulus

$R \quad$ universal gas constant

$T$ temperature

$T_{\mathrm{g}} \quad$ glass transition temperature

$T_{\text {Max }}$ maximum degradation temperature

$T_{\text {Onset }}$ initial degradation temperature

$v_{\mathrm{e}} \quad$ cross-link density

\section{Introduction}

Bio-based epoxy polymers have been explored in different areas as an environmentally friendly alternative for diglycidyl ether of bisphenol A (DGEBA). ${ }^{1-3}$ Despite its versatility, performance and dominance in the epoxy market, DGEBA is directly derived from bisphenol A (also known as BPA), which in turn is linked to a series of serious health hazards. ${ }^{4-6}$ In this regard, epoxidised vegetable oils (EVOs) have been extensively applied in epoxy formulations due to the advantages associated with the exploration of vegetable oils (VOs), such as renewability, abundance and chemical versatility. ${ }^{7}$ EVO can be used either as a reactive diluent or solely as a source of polymerisable epoxy groups, significantly increasing the renewable content, reducing the environmental impact and providing novel properties to these systems. ${ }^{2,8-10}$ Nevertheless, there are challenges associated with the reduced performance of EVOs and economic disadvantages that hinder the full industrial production of these materials at a competitive level against DGEBA. ${ }^{11,12}$ Additionally, some studies question that the exploitation of edible VOs may negatively affect the security of the food supply chain in the long term. ${ }^{13-15}$

In this scenario, the use of waste vegetable oils (WVOs) previously used in deep-frying emerges as an opportunity to explore a bio-based but non-edible source of triglycerides to produce epoxy polymers and polymers in a more sustainable fashion. The technological exploration of WVO is intrinsically aligned with the concepts of sustainability as it can promote economic, environmental and sociological valorisation of this material. ${ }^{16-20}$ Also, from a life-cycle assessment perspective, WVO can be considered a burdenfree starting material since the environmental impacts associated with the cultivation and use phase (deep-frying process) can be omitted in the production of chemicals from food waste. ${ }^{21}$

In previous studies, the authors' group demonstrated the successful utilisation of epoxidised WVO as a reactive diluent for DGEBA formulations to produce blends with increased bio-based content. ${ }^{22}$ Prior to the epoxidation step, purification methodologies were applied to remove by-products formed during the use phase that are responsible for altering the physical and chemical properties of the oil. ${ }^{23,24}$ Therefore, epoxy polymers produced from purified WVO performed similarly to analogues obtained from neat oil when mixed with DGEBA. These formulations were subsequently used successfully to produce composites with recycled carbon fibre with high tensile performance.

Although the previous investigations produced polymers and composites with satisfactory performance, these systems still present DGEBA as the major component in the formulation, consequently compromising the environmental performance. Therefore, in the present work, the authors investigate the production of bio-based thermoset polymers formed exclusively with epoxy polymers derived from WVO (i.e. absence of DGEBA) and cured with different cyclic anhydrides. Despite the popularity of amine hardeners, EVO-based systems are cured more effectively with 
anhydrides due to their increased chemical affinity with electronrich oxirane rings. ${ }^{25}$ These investigations systematically inspected parameters in the thermoset formulation, such as hardener type, the molar ratio between epoxy groups and hardener and the curing catalyst, to understand and optimise the thermal, chemical and dynamic mechanical properties of the resulting polymers. Moreover, these formulations were compared with analogues produced from neat vegetable oil (NVO) to assess the impact in performance caused by replacing the edible triglycerides by waste materials and with DGEBA formulations to compare the performance of the materials produced in this study against a benchmark material.

\section{Materials and methods}

\subsection{General considerations}

WVO (used in a deep-fry medium for $4 \mathrm{~d}$, a blend of rapeseed/ palm oil approximately $3: 1$ ) and NVO were collected from a food outlet at the University of Warwick, Coventry, UK. Hydrogen peroxide $\left(\mathrm{H}_{2} \mathrm{O}_{2}\right)(30 \% \mathrm{v} / \mathrm{v})$, toluene (puriss. p.a. $\left.>99 \cdot 7 \%\right)$, dichloromethane (puriss. 99\%), phthalic anhydride (PA) (99\%), methyl-hexahydrophthalic anhydride (MHHPA) (96\%, mixture of isomers cis and trans) and 2-methylimidazole (2-MI) (99\%) were supplied by Sigma-Aldrich. Magnesium sulfate $\left(\mathrm{MgSO}_{4}\right)$ (dried), triethylamine (TEA) $(99 \%)$ and sulfuric acid $\left(\mathrm{H}_{2} \mathrm{SO}_{4}\right)$ (solution, $1 \mathrm{M})$ were supplied by VWR International. All chemicals, except the WVO, were used as received.

The characterisation of the starting materials was performed by infrared spectroscopy in attenuated total reflection mode Fouriertransform infrared spectroscopy (ATR-FTIR) and proton nuclear magnetic resonance ( ${ }^{1} \mathrm{H}$ NMR). ATR-FTIR (Cary Tensor 27) spectra were obtained in a range of $4000-500 \mathrm{~cm}^{-1}$, accumulating 32 scans with a resolution of $4 \mathrm{~cm}^{-1}$. ${ }^{1} \mathrm{H}$ NMR spectra (Bruker spectrometers HD Avance III $300 \mathrm{MHz}$ and Bruker Avance III $400 \mathrm{MHz}$, operating at $300 \cdot 129$ and $400 \cdot 046 \mathrm{MHz}$, respectively) were obtained from samples of approximately $0 \cdot 2 \mathrm{~g}$ dissolved in $500 \mu \mathrm{l}$ of deuterated chloroform $\left(\mathrm{CDCl}_{3}\right)$ with tetramethylsilane (Sigma-Aldrich, UK).

\subsection{Synthesis of WVO-based polymers}

For the synthesis of the epoxy polymers, WVO $(100 \mathrm{ml}, 1 \cdot 2 \times$ $10^{-1} \mathrm{~mol}, 2 \cdot 5 \times 10^{-1} \mathrm{~mol}$ of double bonds, 1 equivalent), purified according to a procedure previously developed in the group, was added to a round-bottom flask containing Amberlyst $15^{\circledR}$ $(22 \mathrm{wt} \%)$, toluene $(50 \mathrm{ml}, 50 \mathrm{vol} \%)$ and acetic acid $(7 \cdot 0 \mathrm{ml}, 1 \cdot 2 \times$ $10^{-1} \mathrm{~mol}, 0 \cdot 5$ equivalent). After mixing the solution for $10 \mathrm{~min}$ at $60^{\circ} \mathrm{C}$, hydrogen peroxide $\left(30 \% \mathrm{v} / \mathrm{v}, 58 \mathrm{ml}, 5.0 \times 10^{-1} \mathrm{~mol}, 2\right.$ equivalent) was added dropwise to the mixture over a period of $30 \mathrm{~min}$, and the reaction was left for $6 \mathrm{~h}$ under these conditions. The resulting material was filtered and the crude oil was washed with a solution of $5 \mathrm{wt} \%$ sodium bicarbonate $\left(\mathrm{NaHCO}_{3}\right)$ and $5 \mathrm{wt} \%$ sodium chloride $(\mathrm{NaCl})$ to remove acid residues. The product was dried over magnesium sulfate for $30 \mathrm{~min}$ and then filtered for the removal of the drying agent. The excess solvent was extracted using a rotary evaporator. ${ }^{22,26}$ The product obtained was a yellow oil $(70 \%$ yield). The same procedure was repeated for the NVO, with the number of equivalents adjusted according to the values of degree of unsaturation determined by ${ }^{1} \mathrm{H}$ NMR.

A dynamic mechanical analysis (DMA) (Triton Tritec Dynamic Mechanical Thermal Analyser) was performed using a dual cantilever bending set-up with an oscillating frequency of $1.0 \mathrm{~Hz}$ and displacement of $0.05 \mathrm{~mm}$ from -60 to $100^{\circ} \mathrm{C}$ at a heating rate of $2{ }^{\circ} \mathrm{C} /$ $\mathrm{min}$. Specimens were in the rectangular form of a nominal size of 1.5 $\times 5 \times 24 \mathrm{~mm}^{3}$. Glass transition temperature $\left(T_{\mathrm{g}}\right)$ was defined from $\tan \delta$ against temperature as the maximum of the $\tan \delta$ peak. Weightloss curves were measured by thermogravimetric analysis (TGA) using a Mettler Toledo TGA $1 \mathrm{STAR}^{\mathrm{e}}$ system programmed to heat the samples from 25 to $600^{\circ} \mathrm{C}$, with a heating rate of $10^{\circ} \mathrm{C} / \mathrm{min}$, under a nitrogen gas $\left(\mathrm{N}_{2}\right)$ flow of $100 \mathrm{ml} / \mathrm{min}$. The temperature of initial degradation $\left(T_{\text {Onset }}\right)$ was defined from the onset of the degradation temperature of the major thermal event, and the temperature of maximum degradation $\left(T_{\mathrm{Max}}\right)$ was determined from the curve of the first derivative of weight loss with respect to temperature. A chemical resistance test was performed by immersing samples of approximately $1 \mathrm{~g}$ in vials containing $20 \mathrm{ml}$ of water, sodium hydroxide $(\mathrm{NaOH})(1 \mathrm{M})$, sulfuric acid $(1 \mathrm{M})$ and toluene. These vials were kept at room temperature for $7 \mathrm{~d}$, and changes in the weight and physical aspects were calculated for each pair of formulation/solution.

\subsection{Preparation of thermoset polymers}

Bio-based epoxy polymers were produced and characterised from purified waste vegetable oil (PVO) and NVO according to procedures published previously. $^{22}$ Approximately $10 \mathrm{~g}$ of bio-based epoxy polymer, (epoxidised purified vegetable oil (EPVO) or epoxidised NV (ENVO)) were added to a round-bottom flask, and then a certain amount of hardener was added to the system. The hardener-to-epoxy polymer ratio was varied from $0 \cdot 8: 1 \cdot 0$ to $1 \cdot 4: 1 \cdot 0$, producing polymer systems given in Table 1 . Heating $\left(140^{\circ} \mathrm{C}\right)$ was employed to ensure phthalic anhydride solubilisation, while MHHPA was added to the system at room temperature since it is liquid at normal conditions. In sequence,

Table 1. Range of formulations created from VO-based resins and anhydrides cured with TEA and 2-MI

\begin{tabular}{lcccc}
$\begin{array}{l}\text { Resin } \\
\text { origin }\end{array}$ & $\begin{array}{c}\text { Curing } \\
\text { agent }\end{array}$ & $\begin{array}{c}\text { Molar } \\
\text { ratio (HE) }\end{array}$ & $\begin{array}{c}\text { Entry } \\
\text { (TEA) }\end{array}$ & $\begin{array}{c}\text { Entry } \\
\text { (2-MI) }\end{array}$ \\
\hline ENVO & MHHPA & $0 \cdot 8: 1 \cdot 0$ & 1 & 17 \\
& & $1 \cdot 0: 1 \cdot 0$ & 2 & 18 \\
& $1 \cdot 2: 1 \cdot 0$ & 3 & 19 \\
& & $1 \cdot 4: 1 \cdot 0$ & 4 & 20 \\
& PA & $0 \cdot 8: 1 \cdot 0$ & 5 & 21 \\
& & $1 \cdot 0: 1 \cdot 0$ & 6 & 22 \\
& & $1 \cdot 2: 1 \cdot 0$ & 7 & 23 \\
EPVO & $1 \cdot 4: 1 \cdot 0$ & 8 & 24 \\
& MHHPA & $0 \cdot 8: 1 \cdot 0$ & 9 & 25 \\
& & $1 \cdot 0: 1 \cdot 0$ & 10 & 26 \\
& & $1 \cdot 2: 1 \cdot 0$ & 11 & 27 \\
& & $1 \cdot 4: 1 \cdot 0$ & 12 & 28 \\
& & $0 \cdot 8: 1 \cdot 0$ & 13 & 29 \\
& & $1 \cdot 0: 1 \cdot 0$ & 14 & 30 \\
& & $1 \cdot 2: 1 \cdot 0$ & 15 & 31 \\
& & $1 \cdot 4: 1 \cdot 0$ & 16 & 32
\end{tabular}


$3 \mathrm{~mol} \%$ (in relation to the epoxy amount) of the curing catalyst (TEA or 2-MI) were added to the flask. The mixture was kept under stirring for $3 \mathrm{~min}$ to ensure homogeneity, and then the solution was transferred to silicone moulds. The formulations were placed in an oven (Vacuum Oven Fistreem) at $140^{\circ} \mathrm{C}$ for $16 \mathrm{~h}$, and the resulting thermoset polymers were post-cured at $160^{\circ} \mathrm{C}$ for $2 \mathrm{~h}$. The full description of the formulations is presented in Table 1 .

\section{Results and discussions}

\subsection{General considerations}

The study was designed to assess differences in the performance of bio-based thermoset polymers produced from waste oil-based epoxy polymers and analogous materials from conventional VO. Therefore, this comparison permits the identification of the effect of the oil use phase (frying process) in the properties of the resulting polymers, as well as the understanding of how to maximise the performance of these systems. Figure 1 summarises the preparation steps of the thermoset polymers, from the purification of the WVO (leading to the formation of PVO) to the curing with cyclic anhydrides. Features such as the unsaturation degrees of NVO and PVO (2.88 and $2 \cdot 18$, respectively), as well as the number of epoxy rings per triglyceride unit $(2 \cdot 66$ and $2 \cdot 08$, respectively), were defined by ${ }^{1} \mathrm{H}$ NMR. Although these oils present a lower degree of unsaturation in comparison to other VO used for the production of epoxy polymers (e.g. linseed oil -6.6 double bonds per triglyceride), these blends of rapeseed/palm are a more realistic representation of oils commonly used for cooking worldwide. ${ }^{27,28}$

\subsection{Thermal stability of the bio-based polymers}

The exceptional thermal stability of thermosets is one of the main characteristics that differentiate them from thermoplastics and is crucial for some of their unique applications. Therefore, it is imperative to compare the thermal degradation behaviour of bio-based polymers from WVO with those observed for neat oil and commercial DGEBA polymer samples. Thermal stability was evaluated through the mass-loss events detected in the thermogravimetric curves (from 25 to $600^{\circ} \mathrm{C}$ ) (Figures 2(a)
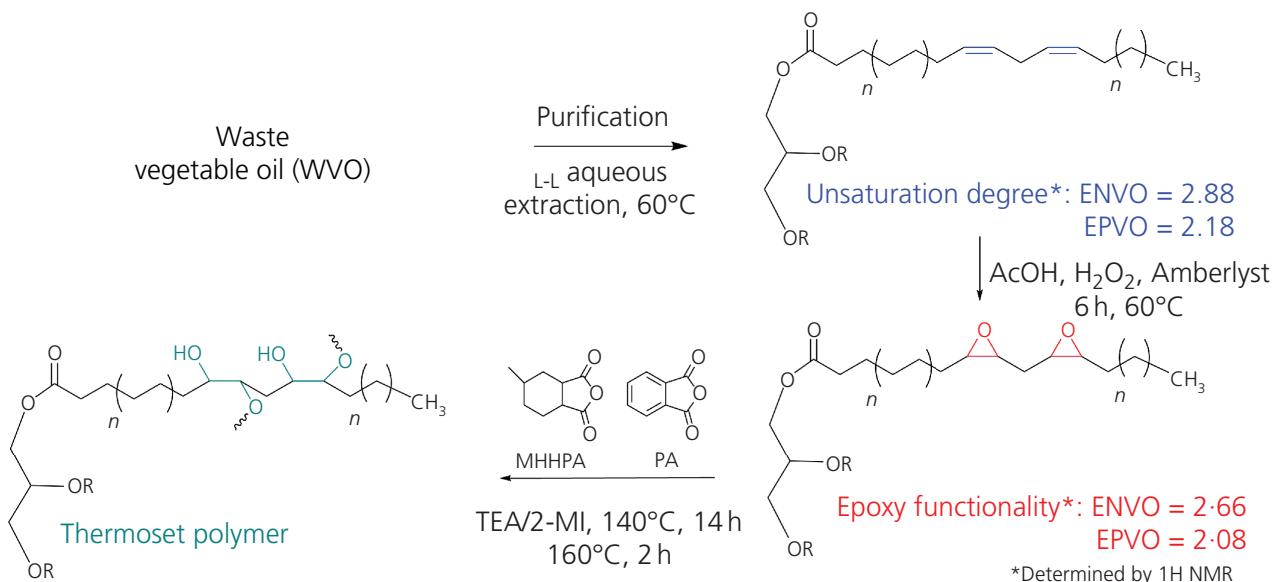

Figure 1. Production of bio-based thermoset polymers from WVO

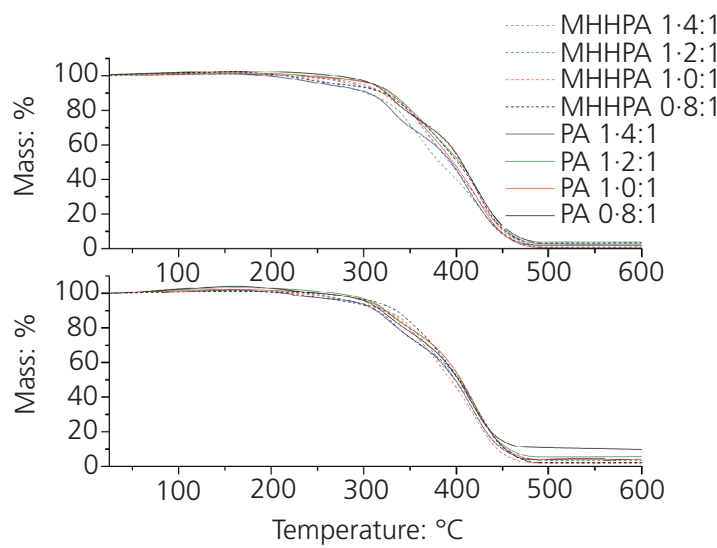

(a)

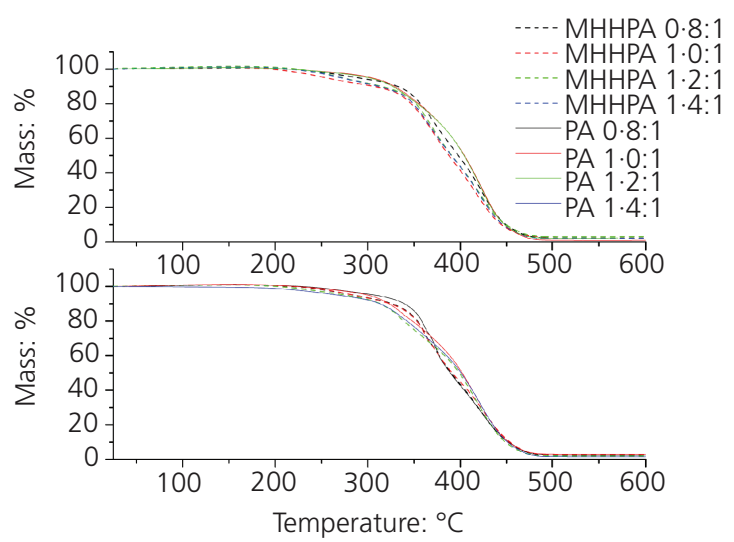

(b)

Figure 2. Thermograms of the polymers from formulations: (a) ENVO-based (top) and EPVO-based (bottom) catalysed with TEA and (b) ENVO-based (top) and EPVO-based (bottom) catalysed with 2-Ml, from 25 to $600^{\circ} \mathrm{C}$, under nitrogen gas atmosphere 
and 2(b)). Despite previous studies showing that the thermal decomposition of EVO-based polymers can occur in a single step, formulations investigated in this study presented a two-stage decomposition, with minor and major events. ${ }^{29,30}$ The first thermal event, observed at approximately $215^{\circ} \mathrm{C}$, corresponded to the thermal decomposition of low-molecular-weight molecules that are unincorporated into the network - that is, unreacted curing agents. These events coincided with the thermal decomposition of the curing agents $\left(213.9\right.$ and $230 \cdot 6^{\circ} \mathrm{C}$ for PA and MHHPA, respectively). The following weight-loss event observed at $c .310^{\circ} \mathrm{C}$ represented the major degradation step. This phenomenon is related to the combined thermal decomposition of triglycerides and the anhydride moieties, which consequently led to the destruction of the network integrity. This behaviour is commonly observed for thermosets produced from EVO and was evidenced by TGA/FTIR/gas chromatography-mass spectrometry studies carried out by Jin and Park ${ }^{31}$ and Tan and Chow. ${ }^{32}$

Table 2 presents the values of $T_{\text {Onset }}$ and $T_{\text {Max }}$ for all thermoset formulations and for the constituents that originated the polymers. The anhydride content, given by the molar ratio, proved to be the main agent that influences this property, and networks richer in anhydride were demonstrated to have reduced thermal stability. This can be seen as a consequence of the reduced thermal stability of the anhydride moiety in comparison with the triglycerides moiety. ${ }^{22}$ In other words, the network becomes more abundant in the less thermally stable component, thereby degrading at reduced temperatures. Moreover, the minor degradation event observed at lower temperatures became increasingly more significant at higher molar ratios, meaning that a more substantial proportion of unreacted anhydrides were not incorporated into the network.

The strategy of replacing neat oil with WVO in the formulations was demonstrated to cause no significant effect regarding the

Table 2. Initial degradation temperature $\left(T_{\text {Onset }}\right)$ and maximum degradation temperature $\left(T_{\mathrm{Max}}\right)$ of polymer produced from formulations 1-32 and their components

\begin{tabular}{lccccc} 
Entry & $T_{\text {Onset: }}{ }^{\circ} \mathbf{C}$ & $T_{\text {Max: }}:{ }^{\circ} \mathbf{C}$ & Entry & $T_{\text {Onset }}:{ }^{\circ} \mathbf{C}$ & $T_{\text {Max: }}{ }^{\circ} \mathbf{C}$ \\
\hline 1 & $323 \cdot 5$ & $447 \cdot 4$ & 17 & $310 \cdot 1$ & $427 \cdot 6$ \\
2 & $304 \cdot 6$ & $425 \cdot 2$ & 18 & $309 \cdot 2$ & $435 \cdot 3$ \\
3 & $289 \cdot 9$ & $423 \cdot 9$ & 19 & $302 \cdot 0$ & $432 \cdot 4$ \\
4 & $291 \cdot 4$ & $425 \cdot 1$ & 20 & $295 \cdot 5$ & $420 \cdot 8$ \\
5 & $316 \cdot 7$ & $415 \cdot 1$ & 21 & $310 \cdot 5$ & $415 \cdot 8$ \\
6 & $308 \cdot 2$ & $410 \cdot 9$ & 22 & $305 \cdot 4$ & $413 \cdot 4$ \\
7 & $306 \cdot 9$ & $420 \cdot 7$ & 23 & $303 \cdot 6$ & $413 \cdot 3$ \\
8 & $304 \cdot 6$ & $414 \cdot 5$ & 24 & $300 \cdot 1$ & $414 \cdot 0$ \\
9 & $314 \cdot 5$ & $422 \cdot 8$ & 25 & $321 \cdot 2$ & $423 \cdot 2$ \\
10 & $312 \cdot 6$ & $424 \cdot 6$ & 26 & $317 \cdot 9$ & $437 \cdot 4$ \\
11 & $306 \cdot 6$ & $423 \cdot 6$ & 27 & $310 \cdot 4$ & $423 \cdot 6$ \\
12 & $302 \cdot 8$ & $427 \cdot 2$ & 28 & $308 \cdot 4$ & $422 \cdot 0$ \\
13 & $302 \cdot 0$ & $414 \cdot 3$ & 29 & $318 \cdot 5$ & $422 \cdot 9$ \\
14 & $300 \cdot 2$ & $423 \cdot 4$ & 30 & $315 \cdot 9$ & $424 \cdot 6$ \\
15 & $298 \cdot 3$ & $421 \cdot 0$ & 31 & $310 \cdot 2$ & $423 \cdot 6$ \\
16 & $293 \cdot 8$ & $419 \cdot 5$ & 32 & $308 \cdot 6$ & $427 \cdot 2$ \\
MHHPA & $230 \cdot 6$ & $272 \cdot 3$ & PA & $213 \cdot 9$ & $245 \cdot 4$ \\
ENVO & $365 \cdot 7$ & $405 \cdot 22$ & EPVO & $364 \cdot 0$ & $406 \cdot 7$
\end{tabular}

thermal stability of the thermosets since $T_{\text {Onset }}$ and $T_{\text {Max }}$ presented no relationship with the origin of the polymer. This observation is aligned with previous reports that revealed that there is no direct connection between the degree of functionality of EVO and the thermal stability of the resulting thermosets. ${ }^{31}$ The choice of the curing catalyst also demonstrated no particular tendency as both sets of formulations behaved similarly.

\subsection{Dynamic mechanical properties}

DMAs were performed to determine the viscoelastic response and the mechanical properties of the bio-based polymers in a range of temperature. Figures 3(a) and 3(b) show the curves of storage modulus against the temperature of compositions catalysed with TEA (T_ENVO and T_EPVO series) and with 2-MI (MI_ENVO and MI_EPVO series), respectively. These curves revealed the dependence of the maximum storage modulus $\left(E^{\prime}\right)$ with the hardener molar ratio and with the anhydride selection. Anhydriderich formulations (high molar ratio) produced polymers with superior $E^{\prime}$ as consequence of the superior molecular rigidity of the hardeners in comparison to the aliphatic backbone of the EVOs. Consequently, the more hardener in the formulation, the stiffer is the polymer network. In addition, EVO-rich polymers reached the rubbery plateau at lower temperatures in comparison to anhydride-rich formulations, demonstrating the effect of the mobility gain provided by the aliphatic moieties. These findings illustrate the ability to control the polymer properties according to the hardener:epoxy molar ratio balance.

Regarding the effect of the selection of the hardener on the properties, formulations produced with PA presented higher storage modulus in comparison to MHHPA. This result is a consequence of the superior rigidity of the PA molecular structure, which displays an aromatic structure, against the cycloaliphatic backbone found in MHHPA. No relationship regarding the oil origin and the initial $E^{\prime}$ could be derived as values were similar. Nevertheless, formulations presented more prominent differences when $E^{\prime}$ is analysed at $25^{\circ} \mathrm{C}$ (considered as a working temperature). ENVO-based polymers presented superior $E^{\prime}\left(25^{\circ} \mathrm{C}\right)$ compared with EPVO analogues, demonstrating that temperature is an important factor when comparing both sets of polymers since it interferes with the chain mobility.

To understand further the changes in the mechanical properties of these thermosets with temperature variation and the differences between the ENVO- and EPVO-based formulations, the glass transition temperature $\left(T_{\mathrm{g}}\right)$ of the polymers was investigated and calculated from the maximum peak of $\tan \delta$ curves (Figures 4(a) and 4(b)). Values for $T_{\mathrm{g}}$ are presented in Table 3. Although the $T_{\mathrm{g}}$ could have been inferred from dynamic differential scanning calorimetry runs, this transition was not clearly defined in the thermograms since this relaxation occurred in a broad range of temperatures, therefore not providing a precise value for the transition. On the other hand, DMA data provided a direct measure of the transition due to chain mobility gain, and the use of the maximum of the $\tan \delta$ peak enabled a clearer identification of the $T_{\mathrm{g}}$. 

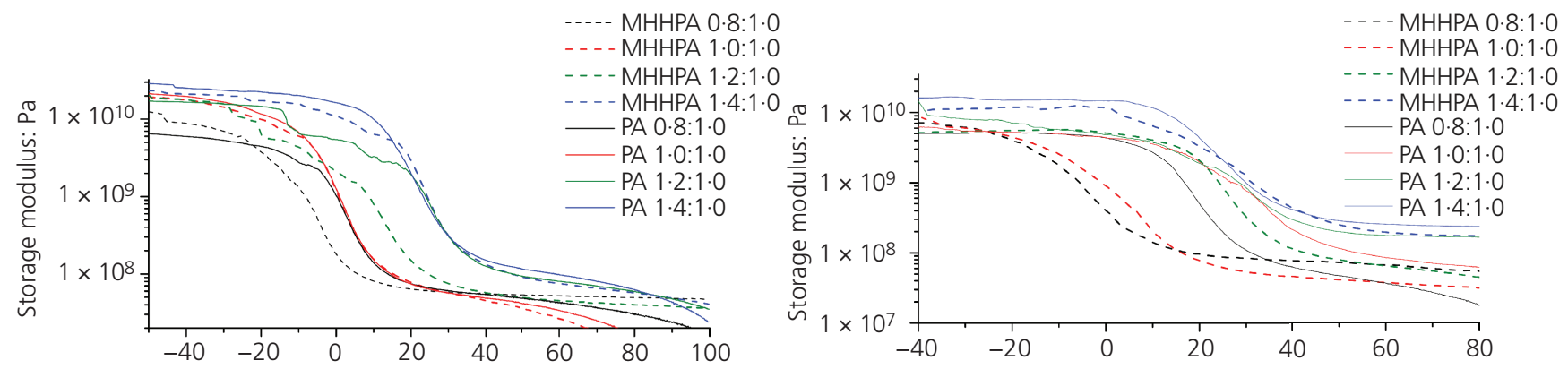

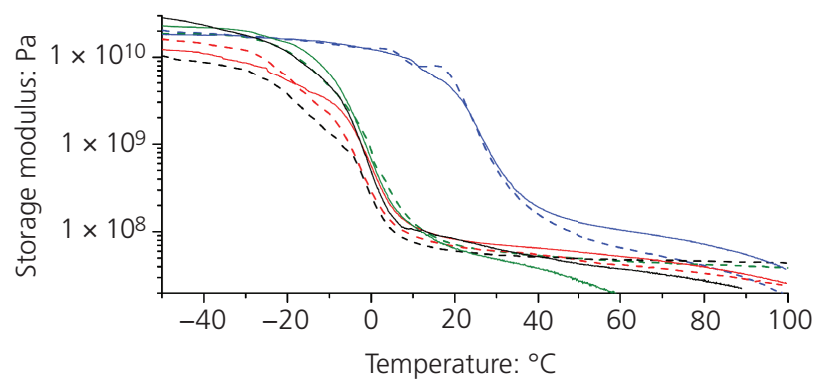

(a)

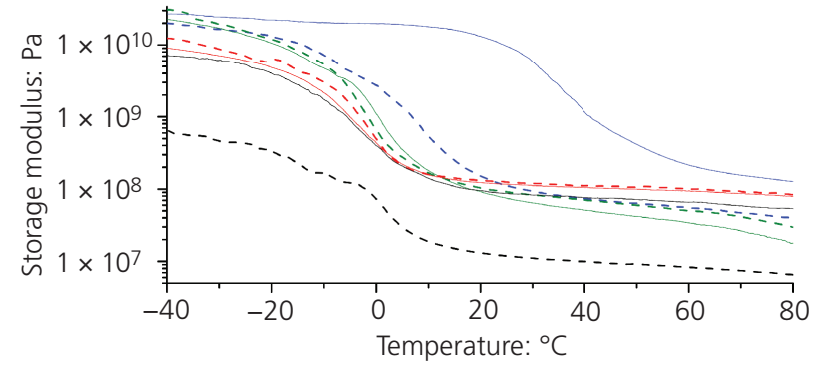

(b)

Figure 3. Curves of storage modulus against temperature for polymers produced with (a) TEA and (b) 2-Ml as catalyst. Top curves derive from neat oil-based polymers and bottom curves from waste oil-based polymers
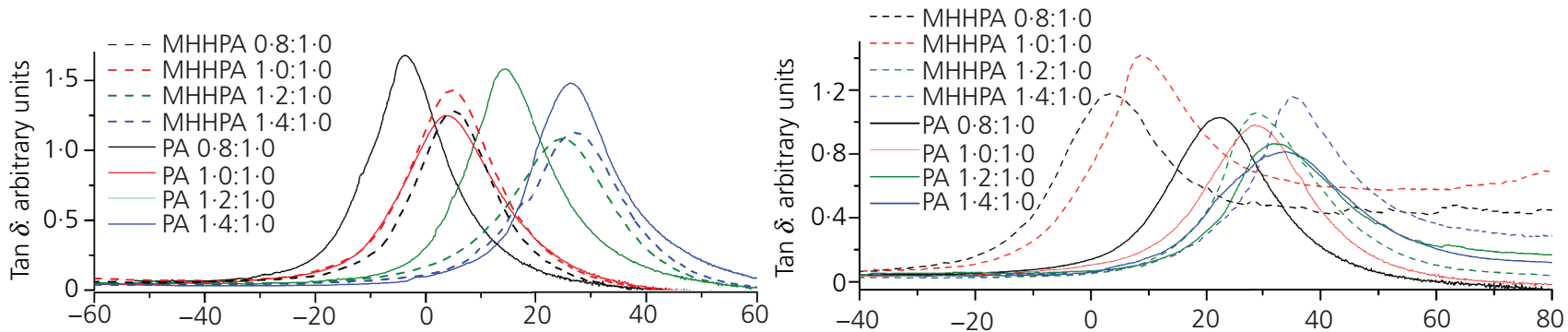

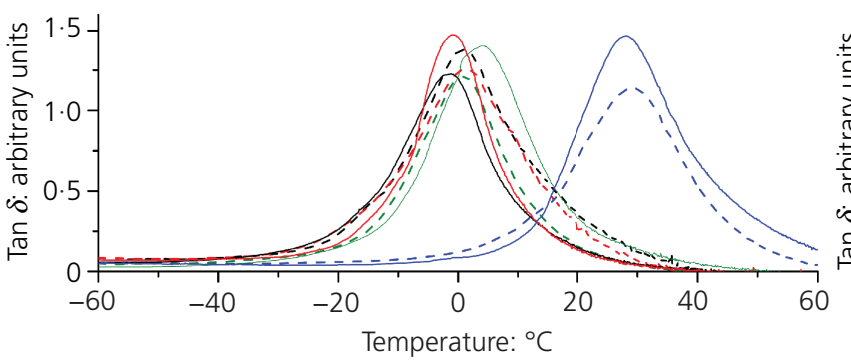

(a)

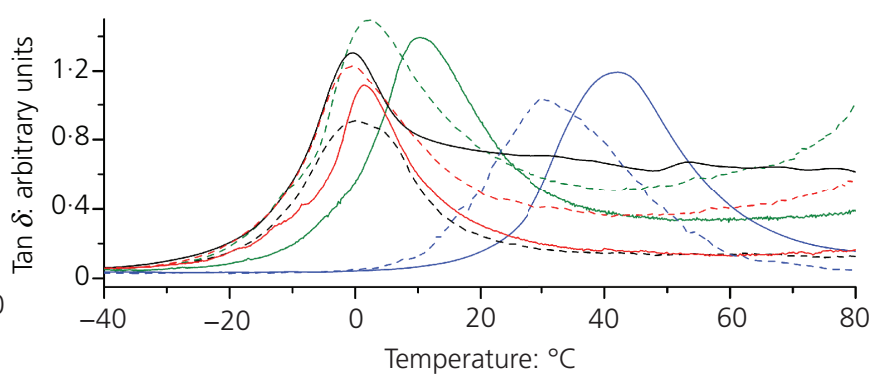

(b)

Figure 4. Curves of $\tan \delta$ against temperature for polymers produced with (a) TEA and (b) 2-Ml as catalyst. Top curves derive from neat oil-based polymers and bottom curves from waste oil-based polymers

Results revealed a strong dependence of the $T_{\mathrm{g}}$ with the combination of parameters covered in this study (hardener, molar ratio, oil source and catalyst), ranging from $-3 \cdot 4$ to $42 \cdot 5^{\circ} \mathrm{C}$. These values, although smaller in comparison to the commercial

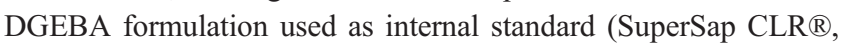
$56 \cdot 3^{\circ} \mathrm{C}$ ), are comparable to similar polyester thermosets produced from EVO reported in the literature (from -8 to $65^{\circ} \mathrm{C}$ ). ${ }^{30}$
All curves presented broad $\tan \delta$ peaks, which are characteristic for the relaxation of heterogeneous networks. ${ }^{33}$ In the context of EVO-based thermosets, this observation is a consequence of the distribution of oxirane groups across the triglyceride backbone, which produces a statistical distribution of double bonds since the starting materials derive from mixed triglycerides. ${ }^{34}$ 
Table 3. Glass transition temperature $\left(T_{\mathrm{g}}\right)$ and cross-link density $\left(v_{\mathrm{e}}\right)$ of formulations $1-32$

\begin{tabular}{lrrrrc} 
Entry & $T_{\mathbf{g}}:{ }^{\circ} \mathbf{C}$ & $\begin{array}{r}V_{\mathrm{e}}: \times 10^{-3} \\
\mathbf{m o l} / \mathbf{c m}^{3}\end{array}$ & Entry & $T_{\mathbf{g}}:{ }^{\circ} \mathbf{C}$ & $\begin{array}{l}\mathrm{V}_{\mathrm{e}}: \times 10^{-3} \\
\mathbf{m o l} / \mathbf{c m}^{3}\end{array}$ \\
\hline 1 & 4.3 & 0.068 & 17 & 3.0 & 0.051 \\
2 & 4.8 & 0.069 & 18 & 9.1 & 0.065 \\
3 & 24.4 & 0.071 & 19 & 28.8 & 0.073 \\
4 & 27.4 & 0.082 & 20 & 35.2 & 0.203 \\
5 & -3.4 & 0.072 & 21 & 22.2 & 0.081 \\
6 & 5.6 & 0.084 & 22 & 28.8 & 0.087 \\
7 & 14.5 & 0.100 & 23 & 31.7 & 0.196 \\
8 & 27.2 & 0.108 & 24 & 34.6 & 0.274 \\
9 & 0.8 & 0.051 & 25 & 0.1 & 0.054 \\
10 & 1.1 & 0.053 & 26 & 2.5 & 0.060 \\
11 & 3.6 & 0.061 & 27 & 27.0 & 0.064 \\
12 & 28.9 & 0.064 & 28 & 30.6 & 0.071 \\
13 & -1.3 & 0.052 & 29 & 0.6 & 0.097 \\
14 & -0.5 & 0.067 & 30 & 2.3 & 0.141 \\
15 & 3.9 & 0.076 & 31 & 10.4 & 0.153 \\
16 & 28.1 & 0.106 & 32 & 42.5 & 0.169
\end{tabular}

Tan $\delta$ curves revealed that formulations with increased anhydride molar ratio resulted in polymers with higher $T_{\mathrm{g}}$, therefore attenuating the contribution of the aliphatic chains towards an overall increase in the network mobility. Furthermore, chain flexibility played an important role at lower anhydride ratio levels: unreacted aliphatic chains act as plasticisers, consequently further reducing the $T_{\mathrm{g}}$ of the systems. ${ }^{31}$ The combination of both effects caused the final mechanical response to be the sum of the contributions of hardener rigidity and the plasticising effect; therefore, the $T_{\mathrm{g}}$ values presented a non-linear increase with the anhydride molar ratio.

The use of polymers from WVO (formulations T_EPVO and MI_EPVO) led to polymers with $T_{\mathrm{g}}$ that generally were smaller than the analogues from neat oil (formulations T_ENVO and MI_ENVO) as a consequence of the reduced number of oxirane rings per triglyceride unit as previously discussed. Therefore, it can be seen that these polymers have a less tightly interconnected network between the epoxy and anhydride moieties and, consequently, presented increased capacity of gaining coordinated mobility. Previous studies demonstrated that EVOs rich in unsaturated bonds (linseed oil, for example) produce polymers with increased $T_{\mathrm{g}}$ when compared to less unsaturated oils, which is due to the formation of a higher cross-link density. ${ }^{35}$ Moreover, these findings explain differences observed for $E^{\prime}\left(25^{\circ} \mathrm{C}\right)$. Dynamic mechanical curves revealed that no secondary transitions (e.g. $T_{\beta}$ ) were identifiable at the low-temperature end of the $\tan \delta$ curve. Discrepancies observed in polymers resulting from a few formulations (T_EPVO_MHHPA $1 \cdot 4: 1$, T_EPVO_PA $0 \cdot 8: 1$ and T_EPVO_PA $1 \cdot 4: \overline{1})$, where the $T_{\mathrm{g}} \mathrm{S}$ were superior to analogues produced from ENVO, can be attributed both to the broad nature of the transition, which makes the definition of a precise value challenging, and to the combination of the plasticising effect previously discussed.

The cross-link density $\left(v_{\mathrm{e}}\right)$, property, which is also directly linked to characteristics such as hardness, impact strength and brittleness of thermoset polymers, was calculated for all formulations through the relationship described by Equation 1 and presented in Table $3 .{ }^{30}$ In this expression, $E^{\prime}$ is the storage modulus at a given temperature; $R$ is the universal gas constant $\left(8314 \times 10^{3} \mathrm{~cm}^{3} \mathrm{MPa} /\right.$ ( $\mathrm{K} \mathrm{mol})$ ); and $T$ is the temperature of the rubbery plateau, described as $\left(T_{\mathrm{g}}+40\right) \mathrm{K}$. This expression permits further understanding of how the degree of functionality and the mechanical properties of the thermosets are related. Values of $v_{\mathrm{e}}$ demonstrate that the increase in molar ratio led to a denser network on all systems as a consequence of a higher availability of cross-linking units, meeting previous observations about the relationship between $v_{\mathrm{e}}$ and hardener molar ratio. ${ }^{36}$

1. $v_{\mathrm{e}}=\frac{E^{\prime}}{3 R T}$

Polymers produced from WVO presented smaller values of $v_{\mathrm{e}}$ when compared to analogues produced from ENVO, which supports the hypothesis that polymers produced from WVO have fewer cross-links due to the lower functionality of the polymer. In addition, thermosets cured with 2-MI as catalyst presented higher $v_{\mathrm{e}}$ than those produced from TEA, corroborating the superior values of $T_{\mathrm{g}}$ previously observed for series MI_ENVO and MI EPVO in comparison to T ENVO and T EPVO. Differences caused by using these catalysts are a consequence of the higher catalytic activity of imidazoles compared with tertiary amines in the initiation step, therefore facilitating the creation of the network. $^{37}$ The increase of the anhydride ratio also led to the increase of $v_{\mathrm{e}}$ in all formulations, confirming that tighter networks were formed in the presence of a stoichiometric excess of the hardener.

A design of experiment (DOE) approach was utilised to investigate the effects of experimental parameters on the resulting $T_{\mathrm{g}}$ and to calculate the significance of each experimental factor and the secondary interactions. This permitted classifying each parameter according to its contribution towards increasing the $T_{\mathrm{g}}$ of the polymers, therefore providing insights for future studies. The $T_{\mathrm{g}}$ was chosen for this particular analysis due to the importance of this property in terms of defining real-life applications for polymeric materials. A $2^{4}$ factorial experiment was built from the 32 formulations, according to the positive and negative levels presented in Table 4. To build a symmetric factorial, the four levels of anhydride molar ratio were grouped into low (non-stoichiometric and stoichiometric levels, $0 \cdot 8: 1 \cdot 0$ and 1·0:1·0) and high (stoichiometric excess, 1·4:1·0 and 1·2:1·0)

Table 4. Factors and levels used in the design of experiments

\begin{tabular}{lcc} 
Factor & Positive level & Negative level \\
\hline Oil origin (A) & ENVO & EPVO \\
Hardener (B) & PA & MHHPA \\
Molar ratio & High (1.4 and 1.2:1) & Low (1.0 and 0.8:1) \\
Catalyst (D) & 2-Ml & TEA
\end{tabular}


levels. The $T_{\mathrm{g}}$ response was analysed in Minitab 17 (Minitab Ltd, UK) using a stepwise analysis to produce a DOE model containing factors over a $95 \%$ confidence interval.

The Pareto chart (Figure 5) demonstrates that the molar ratio (factor C) is the most statistically significant parameter in regulating the $T_{\mathrm{g}}$ of these polymers, whereas the choice of catalyst

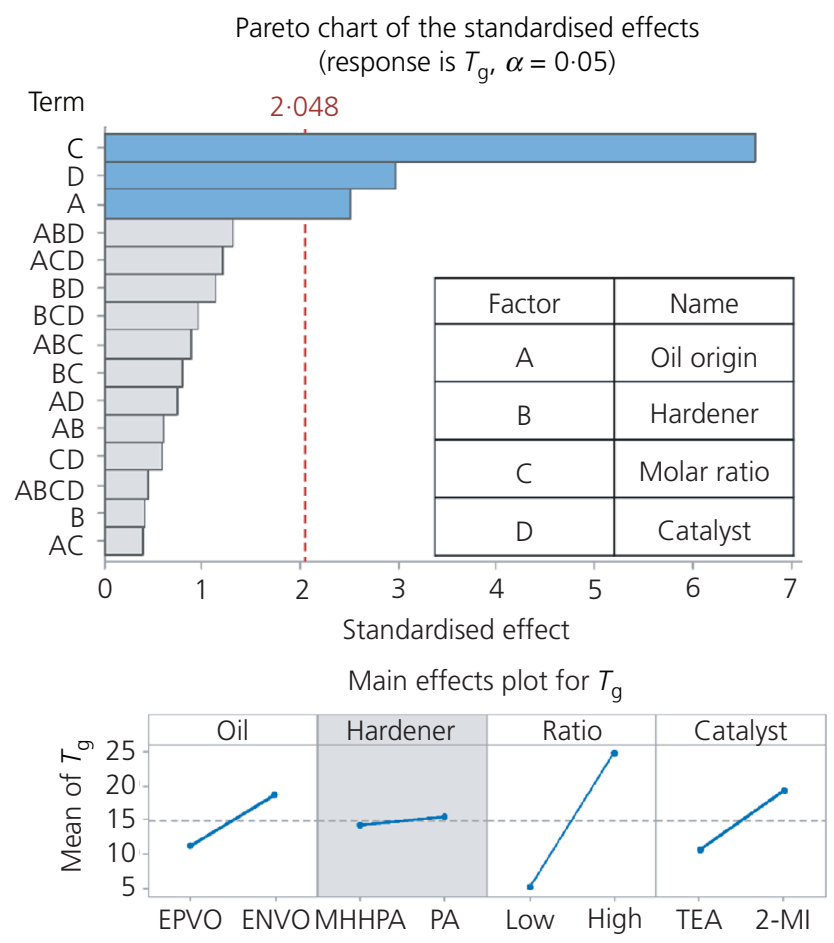

Figure 5. Pareto charts and main effects plot for standardised experimental conditions for the $T_{\mathrm{g}}$ of bio-based epoxies. Greyed out factors represent removed factors due to a significance value lower than $95 \%$ (factor D) and the oil origin (factor A) have smaller contributions passing the significance error bar at $2 \cdot 048$. Figure 5 also presents the main effect plots; however, interaction plots are suppressed since they demonstrated no statistical effect on the $T_{\mathrm{g}}$. The increase in $T_{\mathrm{g}}$ caused by the high level of molar ratio is explained by the combination of increased stiffness of the anhydride and a higher cross-link density previously observed in these formulations.

Therefore, this statistical test demonstrated that the increase in $T_{\mathrm{g}}$ caused by using high contents of anhydride is significant enough to mitigate the reduction in this property caused by the reduced functionality of WVO-based polymers. The DOE also confirmed the importance of the choice of curing catalyst since the increased reactivity of 2-MI led to polymers with superior $T_{\mathrm{g}}$. Interestingly, the selection of hardener (factor B) proved to have no significant impact on the $T_{\mathrm{g}}$ despite hardeners causing differences observed in the storage modulus curves. DMA studies demonstrated that despite the compromise in mechanical properties of the thermoset produced by the reduced functionality of WVO-based polymers in comparison to neat oil, other factors such as the molar ratio of the anhydride and the catalyst can be used to tune the properties of the thermosets and mitigate the losses.

\subsection{Chemical resistance}

The exceptional solvent resistance of thermoset polymers derives from the tightly connected cross-links formed during the curing process, and this characteristic is responsible for defining several applications for these systems in areas such as coatings and sealers. To comprehend the effect of the incorporation of WVObased polymers on this property, the chemical resistance of polymers produced in this study was evaluated according to their relative resistance in water, sodium hydroxide $(1 \mathrm{M})$, sulfuric acid (1 M) and toluene. As schematically presented in Table 5, all formulations showed remarkable stability in aqueous and acidic media as no significant changes were observed either in volume,

Table 5. Chemical resistance of polymers produced from 1-32 in water, sodium hydroxide (1 M), sulfuric acid (1 M) and toluene, $7 \mathrm{~d}$ at room temperature

\begin{tabular}{|c|c|c|c|c|c|c|c|c|c|}
\hline Entry & Water & Sodium hydroxide & Sulfuric acid & Toluene & Entry & Water & Sodium hydroxide & Sulfuric acid & Toluene \\
\hline 1 & - & + & - & * & 17 & - & + & - & * \\
\hline 2 & - & + & - & * & 18 & - & + & - & * \\
\hline 3 & - & + & - & * & 19 & - & + & - & * \\
\hline 4 & - & + & - & * & 20 & - & * & - & * \\
\hline 5 & - & + & - & * & 21 & - & + & - & * \\
\hline 6 & - & * & - & * & 22 & - & * & - & * \\
\hline 7 & - & * & - & * & 23 & - & * & - & * \\
\hline 8 & - & * & - & * & 24 & - & * & - & * \\
\hline 9 & - & + & - & * & 25 & - & + & - & * \\
\hline 10 & - & * & - & * & 26 & - & + & - & * \\
\hline 11 & - & * & - & * & 27 & - & + & - & * \\
\hline 12 & - & * & - & * & 28 & - & * & - & * \\
\hline 13 & - & + & - & * & 29 & - & + & - & * \\
\hline 14 & - & + & - & * & 30 & - & + & - & * \\
\hline 15 & - & + & - & * & 31 & - & * & - & * \\
\hline 16 & - & * & - & * & 32 & - & * & - & * \\
\hline
\end{tabular}

+ , soluble; -, insoluble; *, swelling 
weight or physical aspect. Samples immersed in toluene swelled with weight gains ranging between five and seven times the initial weight. Nevertheless, no samples were completely dissolved in this medium. Precise volume changes were not recorded since the samples' dimension changed irregularly.

Despite the resistance in the previous conditions, the formulations behaved differently in sodium hydroxide: some polymers swelled after immersion for $7 \mathrm{~d}$ while the same conditions led to the complete dissolution of some other group of formulations. This variation in responses is similar to those previously reported for bio-based epoxy polymers produced VOs such as from Karanja oil and Mesua ferrea L. seed oil. ${ }^{29,38}$ The particularly poor chemical resistance of EVO-based thermosets in alkali medium is a consequence of the hydrolysable ester bonds in alkali conditions, therefore deconstructing the network. ${ }^{39}$

In this regard, a parallel can be drawn between the chemical resistance and the $v_{\mathrm{e}}$. As demonstrated by Narute et al., ${ }^{40}$ thermosets with higher $v_{\mathrm{e}}$ possess superior chemical resistance as denser and tighter cross-links hinder the solvent penetration. ${ }^{40}$ By comparing 3 and 5, it can be observed that samples that are displaying cross-link density above the empirical threshold of $0.076 \times 10^{-3} \mathrm{~mol} \mathrm{~cm}^{-3}$ were resistant to complete dissolution due to alkaline hydrolysis of the ester groups. Consequently, formulations produced with increased anhydride molar ratio and cured in the presence of 2-MI presented the most satisfactory performance in chemical resistance tests. In addition, this experiment demonstrated that the origin of the bio-based epoxy polymer played no significant role in defining the chemical resistance of the polymer, therefore supporting the utilisation of WVO concerning this property.

\section{Conclusions}

Thermoset polymers were successfully produced by the combination of bio-based epoxy polymers prepared from WVO with cyclic anhydrides in the presence of two different catalytic systems. This work demonstrates the first application of this material for this particular application. The comparison of these formulations with analogues from NVO revealed that both polymers produced thermosets with similar thermal stability and chemical resistance. Differences in mechanical performance were observed as a function of the degree of functionality of EPVO polymers in comparison with EPVO equivalents. Nevertheless, a statistical analysis identified and classified the most significant parameters with regard to increasing the $T_{\mathrm{g}}$ of these polymers, demonstrating that the contribution of the anhydride molar ratio can mitigate the reduction in properties caused by the reduced functionality of the WVO-based polymer. The inspection of other parameters revealed that 2-MI resulted in polymers with increased $T_{\mathrm{g}}$ and higher cross-link density. Furthermore, increased anhydride/epoxy molar ratio produced thermosets with superior storage modulus, but reduced thermal stability. Therefore, this study recommends the utilisation of high molar ratios of anhydride and 2-MI as catalyst to enable the production of thermosets with competitive mechanical properties from WVO. The optimisation of the formulation was necessary step to permit further studies on the quantification of the impacts of the production of these thermosets. Moreover, these findings open space for the development of a new class of bio-based epoxy polymers (and thermosets) that are more affordable, valorise a waste stream and with minimum impact on the performance that can be applied for the production of composites.

\section{Acknowledgements}

The authors thank the National Council for Scientific and Technological Development (CNPq) (203118/2014-6), Brazil.

\section{REFERENCES}

1. Maiorana A, Ren L, Lo Re G et al. (2015) Bio-based epoxy resin toughening with cashew nut shell liquid-derived resin. Green Materials 3(3): 80-92, https://doi.org/10.1680/jgrma.15.00019.

2. Tan SG and Chow WS (2010) Biobased epoxidized vegetable oils and its greener epoxy blends: a review. Polymer-Plastics Technology and Engineering 49(15): 1581-1590.

3. Seniha Güner F, Yağcı Y and Tuncer Erciyes A (2006) Polymers from triglyceride oils. Progress in Polymer Science 31(7): 633-670.

4. Chen MY, Ike M and Fujita M (2002) Acute toxicity, mutagenicity, and estrogenicity of bisphenol-A and other bisphenols. Environmental Toxicology 17(1): 80-86.

5. Moore-Ambriz TR, Acuña-Hernández DG, Ramos-Robles B et al. (2015) Exposure to bisphenol A in young adult mice does not alter ovulation but does alter the fertilization ability of oocytes. Toxicology and Applied Pharmacology 289(3): 507-514.

6. Okada H, Tokunaga T, Liu X et al. (2008) Direct evidence revealing structural elements essential for the high binding ability of bisphenol A to human estrogen-related receptor- $\gamma$. Environmental Health Perspectives 116(1): 32-38.

7. Biermann U, Bornscheuer U, Meier MAR, Metzger JO and Schäfer HJ (2011) Oils and fats as renewable raw materials in chemistry. Angewandte Chemie International Edition 50(17): 3854-3871.

8. Mosiewicki M, Borrajo J and Aranguren M (2005) Mechanical properties of woodflour/linseed oil resin composites. Polymer International 54(5): 829-836.

9. Kumar S, Samal SK, Mohanty S and Nayak SK (2017) Epoxidized soybean oil based epoxy blend cured with anhydride based crosslinker: thermal and mechanical characterization. Industrial \& Engineering Chemistry Research 56(3): 697-698.

10. Lligadas G, Ronda JC, Galià M and Cádiz V (2013) Renewable polymeric materials from vegetable oils: a perspective. Materials Today 16(9): 337-343.

11. Raquez JM, Deléglise M, Lacrampe MF and Krawczak P (2010) Thermosetting (bio)materials derived from renewable resources: a critical review. Progress in Polymer Science 35(4): 487-509.

12. La Mantia FP and Morreale M (2011) Green composites: a brief review. Composites Part A: Applied Science and Manufacturing 42(6): 579-588.

13. Pimentel D, Marklein A, Toth MA et al. (2009) Food versus biofuels: environmental and economic costs. Human Ecology 37(1): 1-12.

14. Makkar HPS and Becker K (2009) Jatropha curcas, a promising crop for the generation of biodiesel and value-added coproducts. European Journal of Lipid Science and Technology 111(8): 773-787.

15. Lam MK, Tan KT, Lee KT and Mohamed AR (2009) Malaysian palm oil: surviving the food versus fuel dispute for a sustainable future. Renewable \& Sustainable Energy Reviews 13(6-7): 1456-64.

16. Demirbas A (2009) Biodiesel from waste cooking oil via basecatalytic and supercritical methanol transesterification. Energy Conversion and Management 50(4): 923-927. 
17. Salam DA, Naik N, Suidan MT and Venosa AD (2012) Assessment of aquatic toxicity and oxygen depletion during aerobic biodegradation of vegetable oil: effect of oil loading and mixing regime. Environmental Science \& Technology 46(4): 2352-2359.

18. Refaat AA (2009) Different techniques for the production of biodiesel from waste vegetable oil. International Journal of Environmental Science and Technology 7(1): 183-213.

19. Zhang H, Aytun Ozturk U, Wang Q and Zhao Z (2015) Biodiesel produced by waste cooking oil: review of recycling modes in China, the US and Japan. Renewable \& Sustainable Energy Reviews 38: 677-685.

20. Suzuki AH, Botelho BG, Oliveira LS and Franca AS (2018) Sustainable synthesis of epoxidized waste cooking oil and its application as a plasticizer for polyvinyl chloride films. European Polymer Journal 99: $142-149$.

21. Piccinno F, Hischier R, Seeger S and Som C (2015) Life cycle assessment of a new technology to extract, functionalize and orient cellulose nanofibers from food waste. ACS Sustainable Chemistry \& Engineering 3(6): 1047-1055.

22. Fernandes FC, Lehane D, Kirwan K and Coles SR (2017) Epoxy resin blends and composites from waste vegetable oil. European Polymer Journal 89: 449-460.

23. Kulkarni MG and Dalai AK (2006) Waste cooking oil - an economical source for biodiesel: a review. Industrial and Engineering Chemistry Research 45(9): 2901-2913.

24. Choe E and Min DB (2007) Chemistry of deep-fat frying oils. Journal of Food Science 72(5): R77-R86.

25. Wang R and Schuman TP (2013) Vegetable oil-derived epoxy monomers and polymer blends: a comparative study with review. Express Polymer Letters 7(3): 272-292.

26. Petrovic ZS, Zlatanic A, Lava CC and Sinadinovic-Fiser S (2002) Epoxidation of soybean oil in toluene with peroxoacetic and peroxoformic acids - kinetics and side reactions. European Journal of Lipid Science and Technology 104(5): 293-299.

27. Khot SN, Lascala JJ, Can E et al. (2001) Development and application of triglyceride-based polymers and composites. Journal of Applied Polymer Science 82(3): 703-723.

28. Yaakob Z, Mohammad M, Alherbawi M, Alam Z and Sopian K (2013) Overview of the production of biodiesel from waste cooking oil. Renewable \& Sustainable Energy Reviews 18: 184-193.
29. Kadam A, Pawar M, Yemul O, Thamke V and Kodam K (2015) Biodegradable biobased epoxy resin from karanja oil. Polymer 72: 82-92.

30. Gerbase AE, Petzhold CL and Costa APO (2002) Dynamic mechanical and thermal behavior of epoxy resins based on soybean oil. Journal of the American Oil Chemists' Society 79(8): 797-802.

31. Jin FL and Park SJ (2008) Thermomechanical behavior of epoxy resins modified with epoxidized vegetable oils. Polymer International 57(4): 577-583.

32. Tan SG and Chow WS (2010) Curing characteristics and thermal properties of epoxidized soybean oil based thermosetting resin. Journal of the American Oil Chemists' Society 88(7): 915-923.

33. Campanella A, La Scala JJ and Wool RP (2009) The use of acrylated fatty acid methyl esters as styrene replacements in triglyceride-based thermosetting. Polymers Polymer Engineering \& Science 49(12): 2384-2392.

34. Karak N (2012) Vegetable oils and their derivatives. In Vegetable Oilbased Polymers. Woodhead Publishing, Cambridge, UK, pp. 54-56.

35. Kim JR and Sharma S (2012) The development and comparison of bio-thermoset plastics from epoxidized plant oils. Industrial Crops and Products 36(1): 485-499.

36. Ampudia J, Larrauri E, Gil EM, Rodríguez M and Léon LM (1998) Thermal scanning rheometric analysis of curing kinetic of an epoxy resin: I. An anhydride as curing agent. Journal of Applied Polymer Science 71(8): 1239-1245.

37. Supanchaiyamat N, Shuttleworth PS, Hunt AJ, Clark JH and Matharu AS (2012) Thermosetting resin based on epoxidised linseed oil and bio-derived crosslinker. Green Chemistry 14(6): 1759-1765.

38. Das G and Karak N (2009) Epoxidized Mesua ferrea L. seed oil-based reactive diluent for BPA epoxy resin and their green nanocomposites. Progress in Organic Coatings 66(1): 59-64.

39. Manthey NW, Cardona F and Aravinthan T (2012) Cure kinetic study of epoxidized hemp oil cured with a multiple catalytic system. Journal of Applied Polymer Science 125(S2): E511-517.

40. Narute P, Rao GR, Misra S and Palanisamy A (2015) Modification of cottonseed oil for amine cured epoxy resin: Studies on thermo-mechanical, physico-chemical, morphological and antimicrobial properties. Progress in Organic Coatings 88: 316-324.

\section{How can you contribute?}

To discuss this paper, please submit up to 500 words to the journal office at journals@ice.org.uk. Your contribution will be forwarded to the author(s) for a reply and, if considered appropriate by the editor-in-chief, it will be published as a discussion in a future issue of the journal.

ICE Science journals rely entirely on contributions from the field of materials science and engineering. Information about how to submit your paper online is available at www.icevirtuallibrary.com/page/authors, where you will also find detailed author guidelines. 